\title{
Avaliação da influência da biomassa algal no pós tratamento de esgoto doméstico em lagoas de polimento
}

\author{
Evaluation of the influence of algal biomass on post-treatment of domestic sewage in polishing \\ ponds \\ Evaluación de la influencia de la biomasa de algas em el postratamiento de aguas residuales \\ domésticas em lagunas de pulido
}

Recebido: 07/02/2021 | Revisado: 08/02/2021 | Aceito: 13/02/2021 | Publicado: 18/02/2021

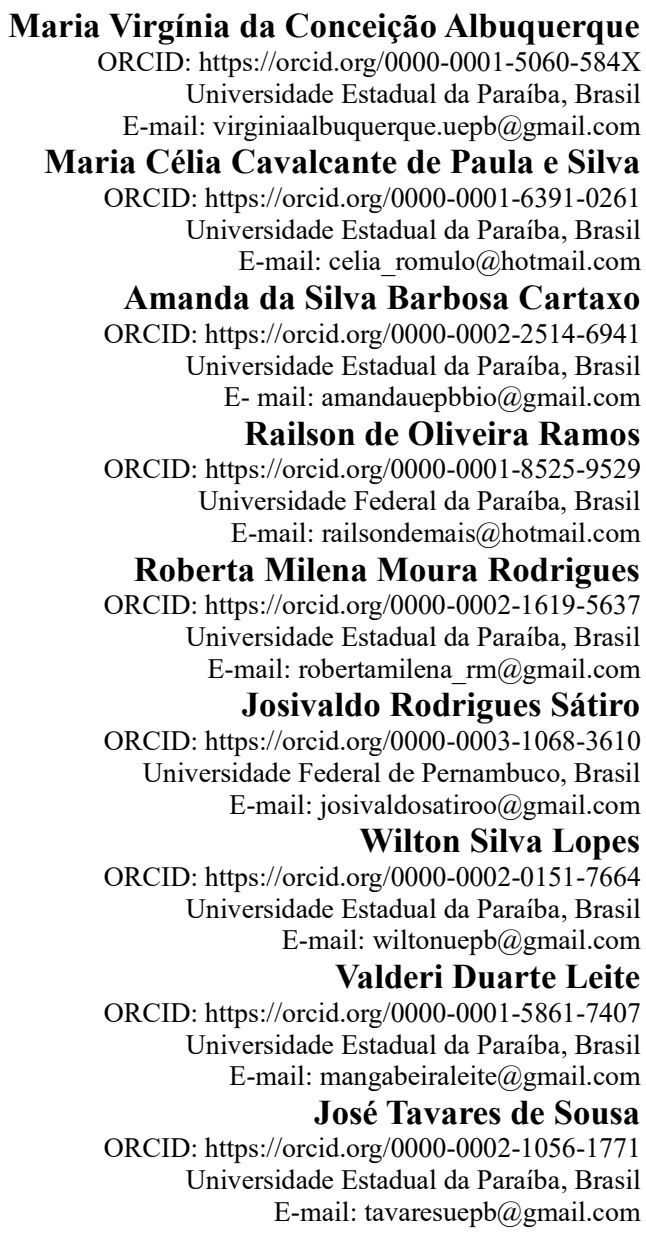

\section{Resumo}

O presente estudo avaliou influência da biomassa algal no pós tratamento de esgoto doméstico em distintas lagoas de polimento. Para tanto, a pesquisa foi realizada na Estação Experimental de Tratamento Biológico de Esgotos Sanitários (EXTRABES), localizada na cidade de Campina Grande-PB, em duas fases experimentais. Na primeira fase, o sistema experimental era constituído de quatro lagoas, na qual duas lagoas foram monitoradas com alimentação contínua (LC $\mathrm{L}_{57}$ e $\mathrm{LC}_{45}$ ) e duas com alimentação semi contínua $\left(\mathrm{LB}_{57}\right.$ e LB $\left.\mathrm{LB}_{45}\right)$. Na segunda fase experimental, foi avaliado o desempenho de três lagoas alimentadas em bateladas ( $\mathrm{LBT}_{45}$ e LB2 ${ }_{45}$ ), e uma alimentada continuamente (LC2 ${ }_{45}$ ). Verificou-se que a determinação das concentrações de clorofila-a pôde proporcionar uma estimativa da biomassa fitoplanctônica, no entanto, elas foram facilmente alteradas, por variações da alta incidência luminosa, temperatura, carga orgânica e TDH. Foi observado que o efluente digerido e a biomassa de algas proveniente da lagoa de transbordo com TDH de 2,4 dias na primeira fase do estudo, propiciou um maior desenvolvimento da comunidade fitoplanctônica. Durante a segunda fase, as lagoas de polimento alimentadas em bateladas sequenciais (LB2 45 e LBT 45 ) apresentaram maiores concentrações de clorofila-a em relação a fase experimental anterior. Concluiu-se que as lagoas de polimento alimentadas em regime 
de batelada se destacaram por apresentarem remoções superiores às lagoas com alimentação contínua e semi contínua, evidenciando-as como promissora no tratamento de esgoto doméstico. Além de obter excelentes resultados, principalmente nas remoções de nutrientes, foi possível tratar uma quantidade superior de afluente em menos tempo de operação.

Palavras-chave: Clorofila-a; Lagoas de estabilização; Tratamento biológico.

\begin{abstract}
The present study evaluated the influence of algal biomass of post-treatment of domestic sewage in different polishing ponds. For this purpose, the research was carried out at the Experimental Station for Biological Treatment of Sanitary Sewers (EXTRABES), located in the city of Campina Grande-PB, in two experimental phases. In the first phase, the experimental system consisted of four lagoons, in which two were monitored with continuous feeding ( $\mathrm{LC}_{57}$ and $\left.\mathrm{LC}_{45}\right)$ and two with semi continuous feeding $\left(\mathrm{LB}_{57}\right.$ and $\left.\mathrm{LB}_{45}\right)$. In the second experimental phase, the performance of three lagoons fed in batches $\left(\mathrm{LBT}_{45}\right.$ and $\mathrm{LB}_{25}$ ), and one fed continuously (LC2 ${ }_{45}$ ) was evaluated. It was found that the determination of chlorophyll-a concentrations could provide an estimate of phytoplankton biomass, however, they were easily altered, due to variations in high light incidence, temperature, organic charge and HRT. It was observed that the digested effluent and the algae biomass from the overflow pond with 2.4-day HDT in the first phase of the study, provided a greater development of the phytoplankton community. During the second phase, the polishing ponds fed in sequential batches (LB2 45 and $\mathrm{LBT}_{45}$ ) showed higher concentrations of chlorophyll-a compared to the previous experimental phase. It was concluded that the polishing ponds fed in batch regime stood out for presenting superior removals to the ponds with continuous and semi continuous feeding, showing them as promising in the treatment of domestic sewage. In addition to obtaining excellent results, mainly in the removal of nutrients, it was possible to treat a larger amount of affluent in less time of operation.
\end{abstract}

Keywords: Chlorophyll-a; Stabilization ponds; Biological treatment.

\title{
Resumen
}

El estudio evaluó la influencia de la biomasa de algas del postratamiento de las aguas residuales domésticas en diferentes lagunas de pulido. Para ello, la investigación se llevó a cabo en la Estación Experimental de Tratamiento Biológico de Alcantarillados Sanitarios (EXTRABES), ubicada en la ciudad de Campina Grande-PB, en dos fases experimentales. En la primera fase, el sistema experimental consistió en cuatro lagunas, en las cuales dos fueron monitoreadas con alimentación continua $\left(\mathrm{LC}_{57}\right.$ y $\left.\mathrm{LC}_{45}\right)$ y dos con alimentación semi continua $\left(\mathrm{LB}_{57}\right.$ y $\left.\mathrm{LB}_{45}\right)$. En la segunda fase experimental, se evaluó el comportamiento de tres lagunas alimentadas en lotes $\left(\mathrm{LBT}_{45}\right.$ y LB2 45 ) y una alimentada de forma continua (LC245). Se encontró que la determinación de las concentraciones de clorofila-a podría proporcionar una estimación de la biomasa del fitoplancton, sin embargo, se alteraron fácilmente, debido a variaciones en la alta incidencia de luz, temperatura, carga orgánica y TRH. Se observó que el efluente digerido y la biomasa de algas del estanque de desbordamiento con TDH de 2.4 días en la primera fase del estudio, proporcionaron un mayor desarrollo de la comunidad de fitoplancton. Durante la segunda fase, las lagunas de pulido alimentados en lotes secuenciales (LB2 45 y LBT 45$)$ mostraron concentraciones más altas de clorofila-a en comparación con la fase experimental anterior. Se concluyó que las lagunas de pulido alimentados en régimen discontinuo se destacaron por presentar extracciones superiores a los estanques con alimentación continua y semi continua, mostrándolos como promisorios en el tratamiento de aguas residuales domésticas. Además de obtener excelentes resultados, principalmente en la remoción de nutrientes, se logró tratar una mayor cantidad de afluentes en menos tiempo de operación.

Palabras clave: Clorofila-a; Lagunas de estabilización; Tratamiento biológico.

\section{Introdução}

As microalgas e cianobactérias são microrganismos aquáticos com importância ecológica e com alta sensibilidade a mudanças ambientais. Em lagoas de estabilização, são responsáveis pela estabilidade da relação simbiótica com as bactérias aeróbias, contribuindo direta e indiretamente, nos processos envolvendo remoção de nutrientes (volatilização, precipitação e assimilação) e remoção dos microrganismos patogênicos (Amengual-Morro et al., 2012). Estes microorganismos diferenciam quanto aos demais, pois possuem capacidade de sintetizar matéria orgânica, apresentam rápido desenvolvimento, multiplicação e súbito desaparecimento, aspectos estes dinâmicos que indicam a qualidade do meio em que estão presentes. Além disso, atuam sobre as condições físico-químicas, modificando a cor, a turbidez, a oxigenação, a alcalinidade e outras propriedades das águas em que habitam (Soldatelli e Schwarzbold, 2010).

Além de contribuírem para o aumento da eutrofização em sistemas biológicos e nos corpos receptores, a comunidade fitoplanctônica é responsável também pela produção de biomassa, que pode ser removida e utilizada na agricultura, piscicultura, 
produção de biocombustíveis, no processo de fixação do $\mathrm{CO}_{2}$, nas indústrias e em outros fins (Ahmad et al., 2011; Lee et al., 2010). Dentre esses, destaca-se a utilização da biomassa de microalgas como fonte de energia renovável, por apresentarem elevada capacidade de reprodução por unidade de área e tempo. Além disso, algumas espécies armazenam elevado teor de lipídios e/ou amido, que pode ser utilizado para a produção de biodiesel ou bioetanol respectivamente (Tabatabaei et al., 2011).

Segundo Zhang et al. (2010), Chi et al. (2011) e Olguín (2012), a composição química dos efluentes de tratamento anaeróbio de esgoto é adequada para crescimento e desenvolvimento das microalgas. Os compostos nitrogenados são convertidos em amônia, fonte importante de nitrogênio para as microalgas (Kassab et al., 2010). Outra vantagem, quanto ao uso de efluente anaeróbio para o crescimento de microalgas, é a presença de $\mathrm{CO}_{2}$ na forma de bicarbonato, além de ácidos orgânicos que são utilizados no crescimento heterotrófico/mixotrófico de algumas microalgas (Larsdotter, 2006). A presença de nitrogênio e fósforo nos efluentes favorece em grande parte o crescimento algal, sendo o nitrogênio um nutriente essencial e constituinte estrutural da biomassa, podendo alcançar entre 1 a $10 \%$ de massa em base seca. Por sua vez, o fósforo, pode atingir de 1 a 1,5\% da massa seca em microalgas, sendo constituinte dos ácidos nucleicos e adenosina fosfatos (Richmond, 2004).

A atividade do fitoplâncton por unidade de biomassa e as respostas à luz é de importância fundamental para o conhecimento dos processos e mecanismos que controlam a transferência de energia e o ciclo de matéria orgânica nas lagoas de polimento. Considerando que o próprio efluente contém microalgas e cianobactérias já adaptadas àquelas condições, e que essa comunidade pode variar com o efluente e suas características, variação temporal, composição taxonômica e crescimento das populações autóctones no efluente, se faz necessário avaliar a concentração da biomassa presentes nestes sistemas, uma vez que, esta pode ser estimada por meio de métodos indiretos, que incluem desde o peso úmido e seco dos microrganismos em um volume conhecido da amostra, ou por métodos diretos como a enumeração direta dos microrganismos, bem como a extração e quantificação da concentração da clorofila - a.

A separação desta biomassa geralmente não é praticada em sistemas de lagoas de polimento, pois requer a utilização de coagulantes e floculantes e estes devido ao custo, limitam a utilização da biomassa. Todavia, as três possibilidades de uso da biomassa removida no polimento de efluentes (alimentação animal, produção de etanol e produção de biogás) podem ser realizadas. Para pequenas cidades, a digestão da biomassa, uma vez que ela produz energia e ao mesmo tempo a biomassa digerida pode ser utilizada como uma fonte de alimentação, mesmo que de baixa qualidade. A matéria orgânica para a realização da digestão anaeróbia, a qual gera o biogás; assim como, existem espécies que apresentam elevada concentração de carboidratos que podem ser utilizados para a geração de açúcares e posterior fermentação e destilação, originando o bioetanol. Assim, após a extração de óleo, a biomassa das algas resultante pode ser transformada em etanol, metano, e, além disso, pode ser utilizada para ração animal ou ser usada como adubo orgânico devido a seu alto teor de nitrogênio e fósforo, ou simplesmente utilizada para a cogeração de energia (eletricidade e calor) (Gris et al., 2010). O uso de biogás provindo de algas para geração de eletricidade pode produzir cerca de $1 \mathrm{kWh}$ de eletricidade/kg de sólidos voláteis de algas (Benemann; Oswald, 1996). Alguns estudos estimam que algumas espécies de algas (Kelp, Ulva, Cladophora) apresentam um potencial de produção de metano de cerca de 0,31 $0,38 \mathrm{~m}^{3} \mathrm{CH}_{4} / \mathrm{kg} \mathrm{SV}$ (Amon et al., 2017). Desse modo, as algas possuem potencial de metano atrativo, quando comparada a outras culturas. Todavia, para que haja maior produção de metano é necessário maximizar a produção de biomassa.

Diante disto, a investigação dos parâmetros que influenciam no desenvolvimento da biomassa de algas é de grande relevância para otimizar o processo de produção, melhorando não apenas o tratamento do efluente como também, gerando mais coprodutos. Portanto, o objetivo desse estudo foi avaliar a influência da biomassa algal na eficiência do pós tratamento de esgoto doméstico, em lagoas de polimento de regime de fluxo em batelada, contínuo e semi contínuo. 


\section{Material e Métodos}

A metodologia utilizada no estudo foi método quali-quantitativo. Segundo Pereira et al., 2018, nos métodos qualiquantitativos, faz-se a coleta de dados quantitativos ou numéricos por meio do uso de medições de grandezas e obtém-se por meio da metrologia, números com suas respectivas unidades. Estes métodos geram conjuntos ou massas de dados que podem ser analisados pelo pesquisador por meio de técnicas matemáticas como é o caso das porcentagens, estatísticas e probabilidades, métodos numéricos, métodos analíticos e geração de equações e/ou fórmulas matemáticas aplicáveis a algum processo.

Para tanto, a pesquisa foi realizada na Estação Experimental de Tratamento Biológico de Esgotos Sanitários

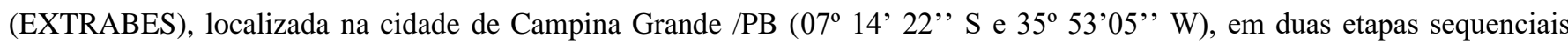
descritas a seguir.

\section{Primeira fase do sistema experimental:}

Constituído de um reator UASB (construído em fibra de vidro; volume de 450 L, tempo de detenção hidráulica (TDH) de oito horas) e quatro lagoas de polimento, sendo duas com fluxo contínuo e duas em regime semi-contínuo (Figura 1). O esgoto doméstico (ED) que alimentava o reator UASB foi proveniente do interceptor leste do sistema de esgotamento sanitário da Companhia de Águas e Esgotos da Paraíba (CAGEPA) em Campina Grande/PB, que passa pelas dependências da EXTRABES e foi aduzido para uma caixa de alimentação de 1.000 litros, seguindo com fluxo continuo, por gravidade até o reator UASB. O efluente desse reator era transferido para um tanque de equalização (TE) que seguia por gravidade para lagoas de fluxo continuo $\left(\mathrm{LC}_{57}\right.$ e $\mathrm{LC}_{45}$ ) e para uma lagoa de transbordo (LT), com capacidade de 430 litros e TDH de 2,4 dias e alimentava as duas lagoas que funcionavam em sistemas semi-contínuo $\left(\mathrm{LB}_{45}\right.$ e $\mathrm{LB}_{57}$ ) (Figura 1). As quatro lagoas foram construídas em alvenaria e suas características físicas são apresentadas na Tabela 1 .

Figura 1. Diagrama esquemático do sistema experimental de tratamento do esgoto com lagoas de polimento - fase 1 .

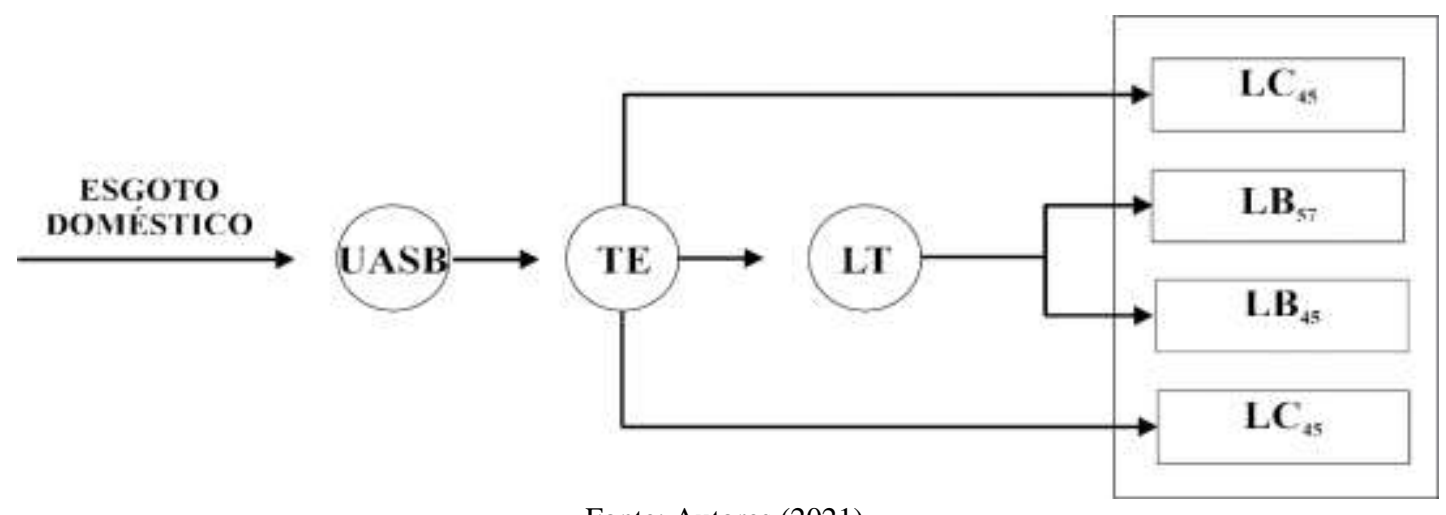

Fonte: Autores (2021).

Tabela 1. Características das lagoas de polimento.

\begin{tabular}{lccccccc}
\hline Lagoas & $\begin{array}{c}\text { Sistema de } \\
\text { alimentação }\end{array}$ & $\begin{array}{c}\text { Profundidade } \\
(\mathbf{c m})\end{array}$ & $\begin{array}{c}\text { Área } \\
\left(\mathbf{m}^{2}\right)\end{array}$ & $\begin{array}{c}\text { Volume } \\
(\mathbf{L})\end{array}$ & $\begin{array}{c}\text { TDH } \\
(\mathbf{d i a s})\end{array}$ & $\begin{array}{c}\text { Vazão } \\
(\mathbf{L} / \mathbf{d i a})\end{array}$ & TAS* \\
\hline $\mathbf{L C}_{57}$ & contínua & 57 & 2 & 1140 & 12 & 95 & 53.7 \\
$\mathbf{L B} \mathbf{5 7}$ & semi-contínua & 57 & 1.76 & 1000 & 10 & 100 & 60.8 \\
$\mathbf{L B} 45$ & semi-contínua & 45 & 1.76 & 792 & 10 & 79 & 48 \\
$\mathbf{L} \mathbf{C}_{45}$ & contínua & 45 & 1.76 & 792 & 12 & 66 & 42.4 \\
\hline
\end{tabular}

*TAS: Taxa de Aplicação Superficial (kgDQOfha $\left.{ }^{-1} \mathrm{dia}^{-1}\right)$ DQOf Demanda Química de Oxigênio Filtrada. Fonte: Autores. 


\section{Segunda fase do sistema experimental:}

O sistema experimental na segunda fase do estudo era constituído de um reator UASB e três lagoas de polimento. O esgoto doméstico (ED) alimentava o reator UASB, e seu efluente era direcionado para um tanque de equalização (TE) que seguia por gravidade para a lagoa de transbordo (LT) com capacidade de 800 litros e TDH de 2 dias, e para o segundo tanque de equalização (TE2) com capacidade de 160 litros, do qual alimentava a LC2 45 através de bomba dosadora, como observa-se na Figura 2.

Figura 2. Diagrama esquemático do sistema experimental de tratamento do esgoto com lagoas de polimento - fase 2.

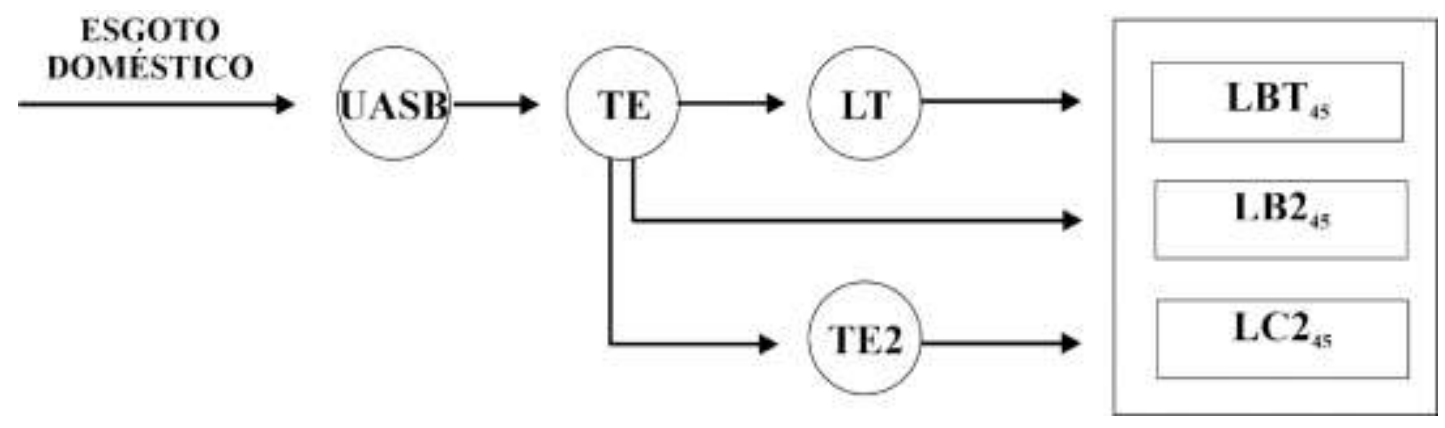

Fonte: Autores (2021).

Nesta fase, as lagoas de polimento foram alimentadas em bateladas sequenciais (LB2 ${ }_{45}$ e $\mathrm{LBT}_{45}$ ), sendo o afluente da $\mathrm{LBT}_{45}$ oriundo da lagoa de transbordo (LT) alimentado através de eletrobombas, e o afluente da LB2 ${ }_{45}$ proveniente do tanque de equalização (TE) seguido por gravidade. O objetivo desta configuração foi comparar o efluente final das duas lagoas em batelada e a influência da LT com TDH de dois dias. O TE tinha capacidade de $500 \mathrm{~L}$ e o tempo de alimentação era de aproximadamente três horas para concluir o volume necessário da batelada da lagoa LB2 ${ }_{45}$ de $616 \mathrm{~L}$. O afluente da $\mathrm{LBT}_{45}$ permanecia por dois dias na lagoa de transbordo (LT) e seis dias na própria lagoa, enquanto o afluente da $\mathrm{LB} 2{ }_{45}$ permanecia os oito dias na lagoa.

As descargas dos efluentes das lagoas de polimento $\mathrm{LB}_{45}$ e $\mathrm{LBT}_{45}$ eram realizadas a cada oito dias, utilizando a técnica de sifonamento, permanecendo com $10 \mathrm{~cm}$ de volume morto, correspondendo a $22 \%$ do volume da batelada anterior, assim como na LT. O volume morto da $\mathrm{LBT}_{45}$ ficava exposto dois dias, enquanto o afluente da lagoa estava na LT, e o volume morto da LT ficava exposto seis dias até o novo ciclo. Os valores correspondentes ao volume morto, bem como as dimensões e características das lagoas são apresentados na Tabela 2.

Tabela 2. Características das lagoas de polimento.

\begin{tabular}{lccccccc}
\hline Lagoas & $\begin{array}{c}\text { Sistema de } \\
\text { alimentação }\end{array}$ & $\begin{array}{c}\text { Profundidade } \\
(\mathbf{c m})\end{array}$ & $\begin{array}{c}\text { Área } \\
\left(\mathbf{m}^{2}\right)\end{array}$ & $\begin{array}{c}\text { Volume } \\
\text { morto } \\
(\mathbf{L})\end{array}$ & $\begin{array}{c}\text { TDH } \\
(\text { dias })\end{array}$ & $\begin{array}{c}\text { Vazão } \\
(\mathbf{L} / \text { dia) }\end{array}$ & TAS*** \\
\hline LBT $_{45}$ & batelada & 45 & 1,76 & 176 & 6 & $616^{*}$ & 96,2 \\
$\mathbf{L B 2}_{45}$ & batelada & 45 & 1,76 & 176 & 8 & $616^{*}$ & 96,2 \\
$\mathbf{L C 2}_{45}$ & contínua & 45 & 1,76 & --- & 12 & $66^{* *}$ & 82,5 \\
\hline
\end{tabular}

*Vazão total a cada batelada (L) ** L/dia ***TAS: Taxa de Aplicação Superficial (kgDQOfha $\left.{ }^{-1} \operatorname{dia}^{-1}\right)$ DQOf Demanda Química de Oxigênio Filtrada.

A lagoa de polimento $\mathrm{LC} 245$ apresentava regime de alimentação em fluxo contínuo, com TDH de 12 dias e funcionou com as mesmas características operacionais da lagoa $\mathrm{LC}_{45}$ na primeira fase do trabalho experimental. Ambas as lagoas da 
segunda fase experimental tinham $45 \mathrm{~cm}$ de profundidade, pois a diferença de profundidade na primeira fase $(45 \mathrm{~cm}$ e $57 \mathrm{~cm})$ não apresentou diferença significativa entre os resultados obtidos.

Monitoramento do sistema e variáveis analisadas: com frequência semanal (às 8:00 e às 12:00 horas), se procedia à coleta de amostras do ES, do efluente do reator UASB, do efluente da LT e das lagoas de polimento. Nas amostras coletadas as 8 horas da manhã, foram feitas análises físico-químicas: demanda química de oxigênio (DQO), nitrogênio total kjeldahl (NTK), fósforo total $\left(\mathrm{P}_{\text {total }}\right)$, sólidos totais $(\mathrm{ST})$ e as 12 horas foram medidos $\mathrm{pH}$, alcalinidade e clorofila-a. As técnicas das análises seguiram as orientações do Standard Methods for the Examination of Water and Wastewater (APHA, 2012), exceto para alcalinidade total (BUCHAUER, 1998) e clorofila-a (JONES, 1979).

O tratamento estatístico dos dados para os parâmetros abordados, foi realizado com o auxílio dos softwares Excel, Origen e Sisvar. Foi aplicada estatística descritiva, calculando médias, desvio padrão, coeficiente de variação e de variância (ANOVA) fator único, com o objetivo de verificar a existência ou não de diferença significativa de $5 \%(\alpha=0,05)$, entre os dados das lagoas de polimento. Quando houve diferença significativa, onde F foi maior que F crítico, realizou-se a análise de comparação de médias através do Teste Tukey.

\section{Resultados e Discussão}

Os principais estudos de produção de biomassa a partir de esgotos sanitários devem focar tanto na avaliação da remoção de matéria orgânica, nitrogênio, fósforo e outros poluentes, como também o controle das variáveis que otimizem a produção de biomassa (Pittman; Dean; Osundeko, 2011).

Na Tabela 3 estão apresentados os resultados dos parâmetros analisados no processo de monitoração dos sistemas durante a primeira fase do trabalho experimental.

Tabela 3. Valores médios e desvios padrões das variáveis analisadas $-1^{\circ}$ fase.

\begin{tabular}{|c|c|c|c|c|c|c|}
\hline & $\begin{array}{c}\text { ED } \\
\bar{x} \pm \delta\end{array}$ & $\begin{array}{l}\text { UASB } \\
\bar{x} \pm \delta\end{array}$ & $\begin{array}{c}\mathbf{L B}_{57} \\
\bar{x} \pm \delta\end{array}$ & $\begin{array}{c}\mathbf{L B}_{45} \\
\bar{x} \pm \delta\end{array}$ & $\begin{array}{c}\mathbf{L C}_{57} \\
\bar{x} \pm \delta\end{array}$ & $\begin{array}{c}\mathbf{L C}_{45} \\
\bar{x} \pm \delta\end{array}$ \\
\hline $\begin{array}{c}\text { DQO } \\
\left(\mathbf{m g O}_{2} \cdot \mathbf{L}^{-1}\right)\end{array}$ & $586 \pm 131$ & $213 \pm 43$ & $183 \pm 38$ & $175 \pm 37$ & $206 \pm 44$ & $194 \pm 23$ \\
\hline $\begin{array}{l}\text { Sólidos totais } \\
\left(\text { mg.L }^{-1}\right)\end{array}$ & $1299 \pm 80$ & $1114 \pm 93$ & $1240 \pm 44$ & $1242 \pm 135$ & $1272 \pm 12$ & $1297 \pm 126$ \\
\hline pH & $7,4 \pm 0,2$ & $7,5 \pm 0,15$ & $8,2 \pm 0,2$ & $8,3 \pm 0,3$ & $8,4 \pm 0,2$ & $8,7 \pm 0,3$ \\
\hline $\begin{array}{c}\text { Alcalinidade Total } \\
\left(\mathrm{mgCaCO}_{3} . \mathrm{L}^{-1}\right)\end{array}$ & $365 \pm 50$ & $401 \pm 32$ & $333 \pm 33$ & $321 \pm 38$ & $342 \pm 24$ & $295 \pm 27$ \\
\hline 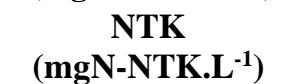 & $65 \pm 16$ & $62 \pm 7$ & $36 \pm 6$ & $39 \pm 5$ & $30 \pm 5$ & $28 \pm 6$ \\
\hline $\begin{array}{c}\text { Fósforo total } \\
\left(\mathrm{mgP} . \mathrm{L}^{-1}\right)\end{array}$ & $8 \pm 1$ & $7 \pm 1$ & $6 \pm 1$ & $5,7 \pm 1$ & $5,8 \pm 2$ & $6,2 \pm 1$ \\
\hline
\end{tabular}

Fonte: Autores.

Na Tabela 4 são apresentados os dados estimados das eficiências de remoções das variáveis analisadas na primeira fase experimental, considerando as concentrações dos afluentes e efluentes. 
Tabela 4. Eficiência de remoção das variáveis analisadas - $1^{\circ}$ fase.

\begin{tabular}{|c|c|c|c|c|c|c|}
\hline & & $\begin{array}{c}\text { UASB-LT } \\
\text { Eficiência } \\
(\%)\end{array}$ & $\begin{array}{c}\text { LT-LB } 57 \\
\text { Eficiência } \\
(\%)\end{array}$ & $\begin{array}{c}\text { LT-LB } 45 \\
\text { Eficiência } \\
(\%)\end{array}$ & $\begin{array}{c}\text { UASB-LC }_{57} \\
\text { Eficiência } \\
(\%)\end{array}$ & $\begin{array}{c}\text { UASB-LC }_{45} \\
\text { Eficiência } \\
(\%)\end{array}$ \\
\hline $\begin{array}{c}\text { DQO }_{\text {total }} \\
\left(\mathrm{mgO}_{2} \cdot \mathrm{L}^{-1}\right)\end{array}$ & 64 & 6 & -- & -- & -- & -- \\
\hline $\begin{array}{l}\text { Sólidos totais } \\
\left(\mathbf{m g} . \mathrm{L}^{-1}\right)\end{array}$ & 14 & 1 & -- & -- & -- & -- \\
\hline $\begin{array}{l}\text { Alcalinidade total } \\
\left(\mathrm{mgCaCO}_{3}^{-} \cdot \mathrm{L}^{-1}\right)\end{array}$ & -- & 3 & 14 & 17 & 15 & 26 \\
\hline $\begin{array}{c}\text { NTK } \\
(\text { mg.N-NTK.L } \\
-1\end{array}$ & -- & 4 & 39 & 35 & 53 & 55 \\
\hline $\begin{array}{c}\text { Fósforo total } \\
\left(\mathrm{mg} \mathrm{P.L} \mathbf{L}^{-1}\right)\end{array}$ & -- & 5 & 16 & 13 & 19 & 13 \\
\hline
\end{tabular}

Fonte: Autores.

Na Tabela 5 e 6, respectivamente são apresentados os resultados dos parâmetros analisados no processo de monitoração dos sistemas, bem como as eficiências de remoções das variáveis analisadas, durante a segunda fase do trabalho experimental.

Tabela 5. Valores médios e desvios padrões das variáveis analisadas - $2^{\circ}$ fase.

\begin{tabular}{|c|c|c|c|c|c|}
\hline & $\begin{array}{c}\text { ED } \\
\bar{x} \pm \delta\end{array}$ & $\begin{array}{l}\text { UASB } \\
\bar{x} \pm \delta\end{array}$ & $\begin{array}{l}\text { LC245 } \\
\bar{x} \pm \delta\end{array}$ & $\begin{array}{l}\mathbf{L B T}_{45} \\
\bar{x} \pm \delta\end{array}$ & $\begin{array}{l}\text { LB245 } \\
\bar{x} \pm \delta\end{array}$ \\
\hline $\begin{array}{c}\text { DQO }_{\text {total }} \\
\left(\mathbf{m g O}_{2} \cdot \mathbf{L}^{-1}\right)\end{array}$ & $796 \pm 379$ & $331 \pm 153$ & \pm 89 & $274 \pm 156$ & $268 \pm 136$ \\
\hline $\begin{array}{l}\text { Sólidos totais } \\
\left(\text { mg.L }^{-1}\right)\end{array}$ & $1400 \pm 229$ & $1044 \pm 56$ & $1083 \pm 87$ & $11127 \pm 142$ & $1098 \pm 143$ \\
\hline pH & $7,4 \pm 0,3$ & $7,4 \pm 0,2$ & $8,8 \pm 0,5$ & $8,7 \pm 0,6$ & $8,8 \pm 0,5$ \\
\hline $\begin{array}{c}\text { Alcalinidade Total } \\
\left(\mathrm{mgCaCO}_{3}-\mathrm{L}^{-1}\right)\end{array}$ & $362 \pm 57$ & $393 \pm 92$ & $258 \pm 41$ & $257 \pm 61$ & $293 \pm 14$ \\
\hline $\begin{array}{c}\text { NTK } \\
\left(\mathbf{m g N}-N T K . L^{-1}\right)\end{array}$ & $66 \pm 18$ & $58 \pm 19$ & $24 \pm 7$ & $25 \pm 8$ & $24,5 \pm 3$ \\
\hline $\begin{array}{c}\text { Fósforo total } \\
\left(\mathrm{mgP} . \mathbf{L}^{-1}\right)\end{array}$ & $10 \pm 3$ & $8,2 \pm 3$ & $4,8 \pm 1$ & $4,9 \pm 2$ & $4,7 \pm 1$ \\
\hline
\end{tabular}

Fonte: Autores.

Tabela 6. Eficiência de remoção das variáveis analisadas $-2^{\circ}$ fase.

\begin{tabular}{|c|c|c|c|c|}
\hline & $\begin{array}{c}\text { ED-UASB } \\
\text { Eficiência } \\
(\%)\end{array}$ & $\begin{array}{c}\text { UASB-LC2 } \\
\text { Eficiência } \\
(\%)\end{array}$ & $\begin{array}{c}\text { UASB-LBT }_{45} \\
\text { Eficiência } \\
(\%)\end{array}$ & $\begin{array}{c}\text { UASB - LB2 } 45 \\
\text { Eficiência } \\
(\%)\end{array}$ \\
\hline $\begin{array}{c}\text { DQO }_{\text {total }} \\
\left(\mathrm{mgO}_{2} \cdot \mathrm{L}^{-1}\right)\end{array}$ & 61 & 27 & 12 & 14 \\
\hline $\begin{array}{c}\text { Sólidos totais } \\
\left(\mathbf{m g . L ^ { - 1 } )}\right.\end{array}$ & 25 & -- & -- & -- \\
\hline $\begin{array}{l}\text { Acalinidade total } \\
\left(\mathrm{mgCaCO}_{3}^{-} . \mathrm{L}^{-1}\right)\end{array}$ & -- & 34 & 35 & 25 \\
\hline $\begin{array}{c}\text { NTK } \\
\left.\text { (mg.N-NTK.L }{ }^{-1}\right)\end{array}$ & -- & 59 & 57 & 57 \\
\hline $\begin{array}{l}\text { Fósforo total } \\
\left(\mathrm{mg} \mathrm{P.L} \mathbf{L}^{-1}\right)\end{array}$ & -- & 41 & 40 & 42 \\
\hline
\end{tabular}

Fonte: Autores. 
A remoção de matéria orgânica e sólidos suspensos no reator UASB, favoreceu a redução da turbidez do afluente das lagoas de polimento, e consequentemente intensificou o desenvolvimento da comunidade fitoplanctônica presente nas lagoas, pelo aumento da penetração da luz, contribuindo para a elevação do pH.

Em lagoa de estabilização a produção de microalgas e remoção de nutrientes de águas residuárias pode ser mais intensa com consumo de $\mathrm{CO}_{2}$ durante o dia. Uma consequência da limitação da fonte de carbono devido ao crescimento das algas em lagoa de alta taxa é o aumento diurno do pH do meio líquido da lagoa (Park e Craggs, 2011). No processo de fotossíntese as microalgas e cianobactérias consumem $\mathrm{CO}_{2}$ do sistema carbônico e seu crescimento pode elevar o pH até valores superiores a 8, realizando então ação tamponante pelo consumo desse gás que é a principal fonte natural de acidez da água (Metcalf e Eddy, 2012).

Foi observado que na primeira fase aos efluentes mantiveram-se com $\mathrm{pH}$ de $8,4 \pm 0,2$ na $^{2} \mathrm{LC}_{57}, 8,2 \pm 0,2$ na $\mathrm{LB}_{45}, 8,3 \pm 0,3$ na $\mathrm{LB}_{45}$ e 8,7 \pm 0,3 na LC 45 . Leite et al. (2005) tratando esgoto doméstico e percolado com DQO de $445 \mathrm{mg} . \mathrm{L}^{-1} \mathrm{em}$ uma série de lagoas de estabilização, sendo uma facultativa e três de maturação com profundidades variando de 0,44 a 0,57 cm e TDH de 15 dias apresentou pH médio de 8,6 no efluente da última lagoa. Na segunda fase experimental as lagoas apresentaram pH de 8,8 \pm 0,5 na LC2 ${ }_{45}, 8,7 \pm 0,6 \mathrm{na} \mathrm{LBT}_{45}$, e 8,8 $\pm 0,5$ na LB2 ${ }_{45}$. O aumento do $\mathrm{pH}$ deve-se ao consumo de $\mathrm{CO}_{2}$ pelas algas e cianobactérias e liberação, na água, de radicais hidroxila, os quais alteram as membranas celulares estimulando a lise e destruição celular, o mesmo efeito é atribuído aos radicais livres de oxigênio. Enquanto os radicais de hidroxila são liberados do sistema carbônico pelo consumo de $\mathrm{CO}_{2}$ exercido pelo fitoplâncton, os radicais livres de oxigênio são formados pela ação da luz solar sobre o OD, ambos têm ação tóxica sobre as membranas bacterianas (Li et al., 2011).

As concentrações médias de sólidos totais no efluente do reator UASB foram de $1114 \pm 93 \mathrm{mgST}$.L ${ }^{-1}$ (Tabela 3) na primeira fase, e $1044 \pm 56 \mathrm{mgST} . \mathrm{L}^{-1}$ (Tabela 5) na segunda fase. Na primeira fase a lagoa de transbordo (LT) indicou redução na concentração de ST (1106 $\pm 58 \mathrm{mgST} . \mathrm{L}^{-1}$ ) (Tabela 3) e subsequentemente redução dos ST no efluente das lagoas de polimento com alimentação em semi contínua, quando comparada com as lagoas com alimentação contínua. Como não foi realizada análise da LT na segunda fase, não foi possível comparar esse comportamento entre as duas fases experimentais, entretanto o efluente final da $\mathrm{LBT}_{45}$ apresentou concentração de ST superior aos das outras lagoas.

Nas duas fases experimentais as lagoas de polimento reduziram a concentração de alcalinidade total em seus efluentes. As mesmas não apresentaram diferença significativa para a análise de variância ANOVA entre a alcalinidade total dos efluentes, sendo F $(1,57)$ menor que F crítico $(3,44)$ para nível de significância de 5\% $(\alpha=0,05)$. De acordo com Cavalcanti $(2009)$ em lagoas de polimento, a redução da alcalinidade é decorrente da remoção de amônia devido à dessorção ser equivalente a remoção de uma base forte ou adição de um ácido forte, no qual 1 meq de alcalinidade é destruído, e da precipitação do carbonato de

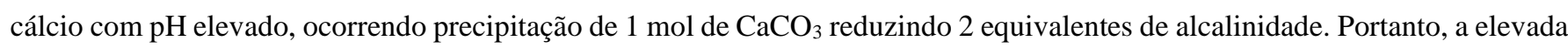
remoção de amônia e a acentuada atividade fotossintética no sistema explicariam, respectivamente, a redução de alcalinidade e elevação de pH ao longo da série de lagoas (Bastos et al., 2010).

As concentrações médias de NTK foram de $30 \pm 5 \mathrm{mg} . \mathrm{L}^{-1}$ na LC $\mathrm{LC}_{57}, 36 \pm 6 \mathrm{mg} \cdot \mathrm{L}^{-1}$ na LB $\mathrm{LB}_{57}, 39 \pm 5 \mathrm{mg} . \mathrm{L}^{-1}$ na $\mathrm{LB}_{45}$ e 28 \pm 6 mg.L-1 ${ }^{-1}$ a LC 45 , (Tabela 3) com eficiência de remoção na ordem de 53\%, 39\%, 35\% e 55\%, respectivamente na $\mathrm{LC}_{57}, \mathrm{LB}_{57}$, $\mathrm{LB}_{45}$ e LC $\mathrm{LC}_{45}$ (Tabela 4). E com eficiência de remoção na ordem de 59\%, 57\% e 57\% (Tabela 6), a segunda fase experimental apresentou concentrações médias de NTK foram de $24 \pm 7 \mathrm{mg} . \mathrm{L}^{-1}$ na LC2 $2_{45}, 25 \pm 8 \mathrm{mg} . \mathrm{L}^{-1}$ na $\mathrm{LBT}_{45}$, e $24 \pm 3 \mathrm{mg} . \mathrm{L}^{-1}$ na $\mathrm{LB}_{45}$, (Tabela 5) respectivamente. Conforme a análise de variância ANOVA não houve diferença significativa entre o NTK do efluente das lagoas de polimento na primeira e segunda fase, sendo $\mathrm{F}(0,09)$ menor que $\mathrm{F}$ crítico $(3,35)$ para nível de significância de $5 \%$ $(\alpha=0,05)$.

É importante destacar que, o fato do esgoto doméstico anaerobiamente tratado possuir elevada concentração de $\mathrm{N}-\mathrm{NH}_{4}{ }^{+}$, torna a remoção encontrada consideravelmente satisfatória. Couto et al. (2015) trataram esgoto doméstico de um reator UASB 
com uma concentração inicial de N-NH${ }_{4}^{+}$inferior, $45,3 \mathrm{mg} \cdot \mathrm{L}^{-1} \mathrm{e}$, também não atingiram os limites de lançamento de nitrogênio amoniacal estabelecidos pela legislação estadual. Neste estudo, a nitrificação também foi a principal forma de transformação do nitrogênio. González-Fernandez et al. (2011) também tiveram a nitrificação como principal processo de transformação de N$\mathrm{NH}_{4}{ }^{+}$no tratamento de efluente anaeróbio em lagoas com produção de microalgas, obtendo até $80 \mathrm{mg} \cdot \mathrm{L}^{-1}$ de $\mathrm{N}-\mathrm{NO}_{3}{ }^{-}$no efluente tratado. Os autores atribuíram a elevada concentração de nitrato ao fato de que, por não ser um efluente facilmente biodegradável, o OD foi utilizado pelas bactérias preferencialmente na nitrificação em relação à oxidação da matéria orgânica.

Camargo Valero (2008) sugere que o aumento das eficiências de remoção de nitrogênio amoniacal em relação ao NTK seria em razão de que grande parte do nitrogênio amoniacal estaria sendo convertido a nitrogênio orgânico devido à assimilação pelas algas. A elevação do $\mathrm{pH}$ em lagoas de polimento favorece a transformação do íon amônia $\left(\mathrm{NH}_{4}{ }^{+}\right)$em amônia livre $\left(\mathrm{NH}_{3}\right)$, gás que se desprende da massa líquida, ocorrendo volatilização de nitrogênio, que é o principal mecanismo de remoção de nitrogênio em lagoas de polimento. Esse fenômeno explica a diferença de comportamento apresentado entre as lagoas com fluxo de alimentação contínuo, no qual a $\mathrm{LC}_{45}$ manteve o efluente com $\mathrm{pH} 8,7$ superior ao das outras lagoas na primeira fase experimental.

A clorofila-a estabelece correlação com DQO e STV e o excessivo desenvolvimento de algas proporciona, portanto, um equivalente acréscimo de sólidos orgânicos em suspensão (sólidos voláteis), os quais são suscetíveis à oxidação química, o que aumenta substancialmente os valores de DQO (Matheus et al., 1989). A inibição da fotossíntese, pode influenciar os níveis de remoção de DQO no meio. Subashchandrabose et al., (2011), ressaltam que uma melhor remoção de compostos com estruturas aromáticas por microalgas ou cianobactérias, é possível quando uma maior eficiência fotossintética é observada no cultivo, estando esse aspecto, relacionado aos níveis de $\mathrm{pH}$ e clorofila a produzida pelo organismo.

Neste estudo, foi observado que o esgoto doméstico da cidade de Campina Grande manteve na primeira fase da pesquisa uma concentração média de DQO bruta de $586 \pm 131 \mathrm{mgO}_{2} \cdot \mathrm{L}^{-1}$ (Tabela 3). O reator UASB apresentou eficiência de remoção de DQO bruta, na ordem de $64 \%$ e $61 \%$, respectivamente, na primeira e segunda fase avaliadas, estando de acordo com as variações esperadas. Segundo Cavalcanti (2009) para explicar a diminuição da DQO, deve ser considerado diferentes mecanismos físico como floculação, sedimentação e migração de algas da superfície da lagoa para o fundo, ressaltando que a transparência do esgoto digerido permitiu elevada incidência de luz na lagoa e migração de algas do topo para o fundo. A redução da DQO também pode ser atribuída, parcialmente a sedimentação dos flocos de lodo anaeróbio presente do efluente do reator UASB.

A análise de variância ANOVA não verificou variações significativas entre o fósforo total do efluente das lagoas de polimento, sendo F $(1,12)$ menor que F crítico $(2,7)$ para nível de significância de $5 \%(\alpha=0,05)$. De acordo com Von Sperling (2002) os principais mecanismos de remoção de fósforo em lagoas de estabilização é a retirada do fósforo orgânico contido nas algas e bactérias através da saída com o efluente final e a precipitação de fosfatos em condições de elevado pH. Além da assimilação pela comunidade fitoplanctônica, o segundo mecanismo justifica a remoção superior apresentada na segunda fase em relação a primeira, visto que as lagoas apresentaram pH médio próxima a 9.

\section{Biomassa algal}

Perez-Garcia et al., (2011) explica a concentração de clorofila, além de estar intimamente ligada com a eficiência fotossintética, também pode prever o momento para a colheita do cultivo, evitando perdas de produtividade global. Assim como em reatores biológicos, as lagoas de estabilização contêm nutrientes para o desenvolvimento dos organismos ali presentes. A ausência ou o desequilíbrio de nutrientes nas lagoas facultativas, de polimento e de maturação proporcionam o desenvolvimento cianobactérias, que segundo Branco (1986), não sedimentam mesmo depois de mortas, dificultando assim a passagem de luz e interferindo na fotossíntese realizada pelas microalgas verdes. Em seguida, ocorre uma diminuição das concentrações de OD e uma consequente redução nos valores de $\mathrm{pH}$. Porém, à noite o excesso de microalgas poderia causar uma demanda de oxigênio 
devido a sua respiração, uma vez que na ausência de luz, cessa a atividade fotossintética e a produção de oxigênio. A clorofilaa, e o OD atingem concentrações mais elevadas no período seco, indicando uma atividade fotossintética mais intensa.

Alguns autores afirmam que a abundância relativa de organismos fitoplanctônicos difere significativamente quando o meio é submetido a diferentes concentrações de $\mathrm{CO}_{2}$ (Low Décarie et al., 2011; Low Décarie et al., 2015; Sutherland et al., 2016). Os mecanismos fisiológicos de cada clado podem influenciar na capacidade dos organismos em absorver e utilizar o $\mathrm{CO}_{2}$ (Kardol et al., 2010), o que altera a capacidade competitiva de cada espécie levando, inclusive a mudanças taxonômicas na comunidade. A Chlorella sp. e Scenedesmus sp. por exemplo, são os gêneros de microalgas que apresentam melhor desempenho, devido sua capacidade de absorção de nitrogênio, matéria orgânica e fósforo, atingindo assim maiores taxas de crescimento (Hoh, Watson, \& Kan, 2016; Makareviciene, Andrulevičiūtè, Skorupskaitè, \& Kasperovičienè, 2011).

As microalgas geradas dentro destes sistemas tendem a ser apresentar em formas de colônias, o que torna mais fácil a sedimentação assim que cessada a turbulência. Assim como nos sistemas convencionais, a matéria orgânica é removida através da oxidação por bactérias heterotróficas, sendo o oxigênio fornecido pela atividade fotossintética de algas. No caso de matéria orgânica particulada, outra via de remoção é a agregação ao floco de alga/bactéria e posterior sedimentação em um decantador (Santiago, 2013). As principais vias de remoção de nutrientes são a assimilação fotossintética, ou seja, incorporada a biomassa algal, e a volatilização do nitrogênio e precipitação do fósforo.

Perez-Garcia et al., (2011) explica a concentração de clorofila, além de estar intimamente ligada com a eficiência fotossintética, também pode prever o momento para a colheita do cultivo, evitando perdas de produtividade global. Normalmente a quantidade de microalgas presente nas lagoas de estabilização é estimada determinando-se a concentração de clorofila-a compreendida entre 500 a $2500 \mu \mathrm{g} . \mathrm{L}^{-1}$, sendo a produtividade da biomassa algal influenciada pela energia solar recebida, disponibilidade de substâncias nutritivas, profundidade da lagoa, tempo de residência e a temperatura. E em sistemas alimentados por águas residuárias, a luz tem freqüentemente um papel de fator limitante e a produtividade, é uma função aproximadamente linear da energia solar total recebida. Na Figura 3 apresenta-se as concentrações de clorofila-a na primeira fase.

Figura 3. Concentrações médias de clorofila-a nas lagoas de polimento $-1^{\circ}$ fase.

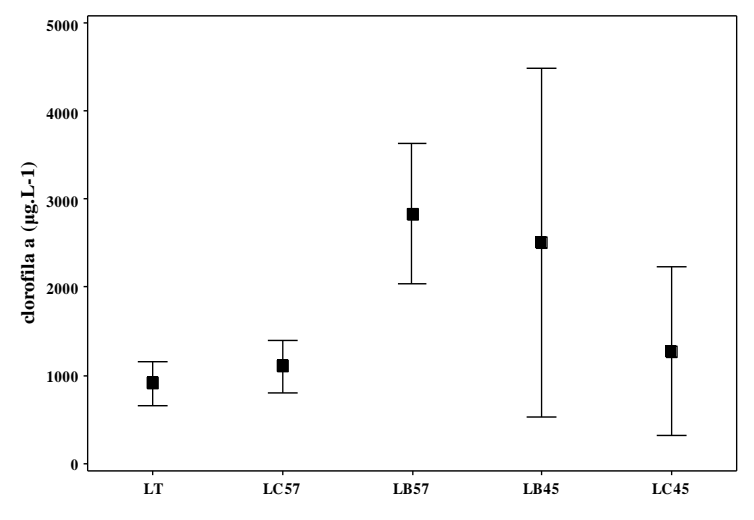

Fonte: Autores.

Foi verificado que o efluente digerido e a massa de algas proveniente da lagoa de transbordo apresentou valores médios de $907 \mu \mathrm{g} . \mathrm{L}^{-1}$ de clorofila-a (Figura 3), o que sugere um maior desenvolvimento da comunidade fitoplanctônica nas lagoas que operaram em sistema semi contínuo. As concentrações médias de clorofila-a nas lagoas $\mathrm{LB}_{57}$ e $\mathrm{LB}_{45}$, foram respectivamente $2837 \mu \mathrm{g} . \mathrm{L}^{-1}$ e $2504 \mu \mathrm{g} . \mathrm{L}^{-1}$ superiores as concentrações das lagoas $\mathrm{LC}_{57}$ e LC 45 , respectivamente de $1104 \mu \mathrm{g} . \mathrm{L}^{-1}$ e $1274 \mu \mathrm{g} . \mathrm{L}^{-1}$ (Figura 3). Cavalcanti (2009) afirma que a lagoa de transbordo com tempo de detenção hidráulica de 1,6 dias é suficiente para manter uma massa expressiva de algas. 
Sabe-se que temperatura da massa líquida exerce elevada influência na remoção do nitrogênio devido a fatores como: aumento dos níveis de clorofila-a, o que determina a alcalinização do meio, fazendo com que $\mathrm{NH}_{3}$ seja volatilizado e também absorvido pela biomassa e exerce influência de forma indireta, pois está relacionado com a intensidade da radiação solar, fator decisivo na remoção do fósforo, uma vez que favorece a atividade fotossintética, responsável pela oxigenação, e consequente alcalinização da massa líquida.

As variações na dominância da biomassa algal geralmente são causadas por mudanças nas condições ambientais como variação sazonal da radiação da energia solar, variação da temperatura, que são conhecidos para afetar sucessões de espécies, bem como parâmetros operacionais, tais como tempo de detenção hidráulica (Park et al., 2011). König (2000) observou flutuações nas concentrações de clorofila-a relacionadas com o movimento das algas ao longo da coluna de água e sua estratificação em diferentes zonas devido a influência da temperatura e da radiação solar. Segundo os autores, o aumento da carga orgânica nas lagoas causou uma redução da biomassa algal. A diminuição da concentração da clorofila-a estaria também relacionada com outros fatores, como o aumento da concentração em amônia, sulfetos e turbidez.

Geralmente a resposta da produção da biomassa de algas com a radiação é linear. Além disso, não somente a radiação influi sobre o desenvolvimento das algas como também as algas interferem na penetração da luz solar. O crescimento de microalgas aumenta com a elevação da temperatura até atingir um valor de temperatura ótima. A partir desta temperatura o crescimento pode ser prejudicado. Sob condições de taxa máxima de crescimento das algas, na presença de nutrientes e condições de luz adequadas, há variação de espécies fitoplactônicas, a temperatura ótima medida geralmente encontra-se entre $28^{\circ} \mathrm{C}$ e $35^{\circ} \mathrm{C}$ (Barroso, 2015).

Os seis meses de monitoramento da primeira fase do estudo, foram representados por alta intensidade luminosa. Conforme os dados disponibilizados pelo Instituto Nacional de Meteorologia (INMET) da estação A313 de Campina Grande$\mathrm{PB}$, a temperatura média às 8 horas era $22^{\circ} \mathrm{C}$, às 12 foi $26^{\circ} \mathrm{C}$, às 14 horas era $28^{\circ} \mathrm{C}$ no período em estudo. Como resultado da atividade fotossintética das algas nas lagoas, houve uma variação diária na concentração de OD. Após o nascer do sol, o OD sobe gradualmente, em resposta à fotossíntese, até atingir um máximo no meio da tarde, depois ele cai até um mínimo durante a noite, quando a fotossíntese cessa e as algas (como também as bactérias), consomem oxigênio através da respiração, a profundidade em que o balanço entre oxigênio produzido e consumido é igual à zero, fenômeno este denominado oxipausa (Mara, 2003; Shilton, 2005).

Algumas espécies de microalgas têm seu crescimento/produtividade otimizada na presença de bactérias. Estas enriquecem o meio com $\mathrm{CO}_{2}$, uma importante fonte de carbono para o cultivo autotrófico de microalgas, ao degradar a matéria orgânica durante o metabolismo celular. No entanto, estudos também apontam que a presença de algumas bactérias fermentadoras é desfavorável, pois tendem a competir com as microalgas pelo carbono dissolvido no meio, e até mesmo utilizar a biomassa microalgal como fonte de energia em seus processos bioquímicos, diminuindo a densidade das microalgas, e tornando-se os microorganismos dominantes no meio de cultivo (Bahadar et al., 2013).

Na segunda fase, as lagoas LC2 $45, \mathrm{LBT}_{45}$ e LB2 45 apresentaram concentrações médias de $812 \mu \mathrm{g} . \mathrm{L}^{-1}, 1204 \mu \mathrm{g} . \mathrm{L}^{-1}$ e 1611 $\mu \mathrm{g} . \mathrm{L}^{-1}$, respectivamente. A lagoa de polimento com fluxo de alimentação em batelada e afluente advindo do tanque de equalização apresentou concentrações superiores de clorofila-a, pois o líquido permaneceu todo no TDH de oito dias na lagoa, favorecendo assim o desenvolvimento da biomassa algal (Figura 4). 
Figura 4. Concentrações médias de clorofila-a nas lagoas de polimento $-2^{\circ}$ fase.

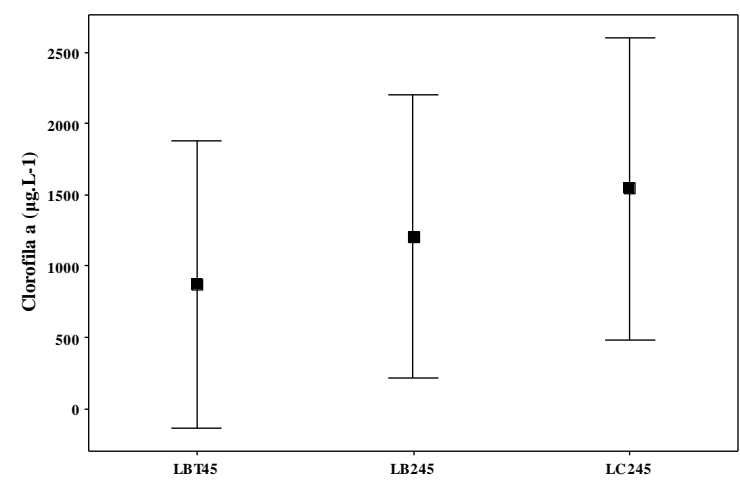

Fonte: Autores.

Estudo realizado por Falco (2005) tratando esgoto doméstico em lagoas de estabilização no Estado de São Paulo obteve valores de clorofila-a nos efluentes variando entre $107 \mu \mathrm{g} . \mathrm{L}^{-1} \mathrm{e} 3.061 \mu \mathrm{g} . \mathrm{L}^{-1}$. Em efluentes de lagoas de estabilização tratando esgoto doméstico no Estado da Paraíba, Ribeiro (2007) observou concentrações de clorofila-a variando de 0 a $4.607 \mu \mathrm{g} . \mathrm{L}^{-1}$.

As lagoas de polimento além de removerem microrganismos patogênicos e nutrientes, reduzem significativamente o tempo necessário de tratamento, quando comparada com o sistema de lagoas convencionais (20-25 dias), produzindo um efluente com qualidade microbiológica parecida. Na superfície dessas lagoas se cria uma camada de espessura de cerca de 1 a 2 cm de biomassa algal. A retirada desse material beneficia a penetração de luz favorecendo o processo fotossintético. Essa biomassa algal produzida nas lagoas de alta taxa pode ser utilizada para produção de bioenergia (Craggs, 2005; Park et al., 2011).

Sabe-se que algumas bactérias durante o tratamento de efluentes domésticos, produzem substâncias poliméricas extracelulares (EPS) auxiliando na agregação das microalgas com as cianobactérias, propiciando em uma biomassa mais estável, sendo possível a colheita e direcionamento para outras atividades, como biogás e biocombustíveis (Wang et al., 2016). A possível utilização da biomassa algal de lagoas de estabilização como fonte de energia renovável tem se mostrado de extrema importância, visto ser perceptível que o mundo vem se preocupando com a crise energética ocasionada pelo uso desenfreado das fontes de combustíveis fósseis. De acordo com os dados do relatório do balanço energético nacional, a oferta interna de energia no Brasil ainda é liderada por fontes não renováveis $(58,1 \%)$ e, destas, 37,3\% são derivadas do petróleo (Brasil, 2018). Tal fato perpetua o aumento descontrolado dos gases do efeito estufa na atmosfera, provocando o aquecimento global e, consequentemente, esse aumento de temperatura sem controle tem ocasionado mudanças climáticas regionais e vários efeitos prejudiciais ao meio ambiente a ao ser humano.

Apesar de não ser realizado neste estudo, é importante considerar que a produção por biomassa algal de bioetanol e o biodiesel são os biocombustíveis líquidos de destaque no cenário sustentável. Mediante rotas biológicas, o bioetanol pode ser produzido com base em qualquer biomassa que contenha quantidades significativas de amido ou açúcares. As microalgas e outros microrganismos oleíferos também têm sido propostos e amplamente estudados como fonte de lipídeos para a produção de biodiesel. Além disto, as microalgas apresentam um ciclo de vida de poucos dias, permitindo colheitas contínuas e diminuindo a logística de armazenagem, necessária para o caso de culturas anuais, e sua habilidade em consumir $\mathrm{CO}_{2}$ como insumo para a fotossíntese (crescimento autotrófico) pode contribuir para uma eventual redução do aquecimento global (Ramos et al., 2017). Com a tendência mundial para crescimento de tecnologias sustentáveis, os mecanismos que visam a produção de biomassa de microalgas vêm despontando, mostrando a eficiência para tratamento de efluentes e remoção de nutrientes inorgânicos de águas residuais, que possibilitam também, a diminuição de emissão de gases do efeito estufa no meio ambiente (Besha et al., 2017). 


\section{Conclusão}

A atividade do fitoplâncton por unidade de biomassa e as respostas à luz são de importância fundamental para o conhecimento dos processos e mecanismos que controlam a transferência de energia e o ciclo de matéria orgânica nas lagoas de polimento. Em ecossistemas aquáticos que recebem altas concentrações de matéria orgânica, como é o caso das lagoas de estabilização, há normalmente um considerável desenvolvimento de fitoplâncton, que se origina a partir de grandes quantidades de nutrientes liberadas no processo de estabilização do resíduo.

A remoção de matéria orgânica e sólidos suspensos no reator UASB, favoreceu a redução da turbidez do afluente das lagoas de polimento, e consequentemente favoreceu o desenvolvimento da comunidade fitoplanctônica presente nas lagoas pelo aumento da penetração da luz, contribuindo para a elevação do pH. A lagoa de transbordo com TDH de 2,4 dias propiciou o desenvolvimento de biomassa algal, intensificando o processo fotossintético, visto que as algas têm papel primordial no funcionamento de lagoas de polimento, além disso, a lagoa de transbordo contribuiu com a sedimentação de sólidos suspensos advindo do efluente do reator UASB.

As lagoas $\mathrm{LBT}_{45}$ e LB2 45 na segunda fase experimental, que funcionaram com alimentação em batelada e TDH de 8 dias não divergiram significativamente da lagoa $\mathrm{LC}_{45}$ com fluxo de alimentação contínua e TDH de 12 dias em relação às remoções de nutrientes. A permanência de $10 \mathrm{~cm}$ de volume morto na lagoa alimentada em batelada, cerca de $20 \%$ da batelada anterior, além de favorecer o desenvolvimento da biomassa algal é uma alternativa em relação à utilização da lagoa de transbordo, visto que o afluente da lagoa pode ser oriundo do reator UASB e não da lagoa de transbordo com TDH maior que 1,6 dias.

Conclui-se que as lagoas alimentadas em batelada se destacaram por apresentarem remoções superiores às lagoas com alimentação contínua e semi contínua, destacando-se como promissora no tratamento de esgoto doméstico. Além de obter excelentes resultados, principalmente nas remoções de nutrientes, foi possível tratar uma quantidade superior de afluente em menos tempo de operação.

A contribuição para estudos posteriores, parte da abrangência da pesquisa, de forma a gerar uma análise ampla sobre a influência da biomassa algal no pós tratamento de esgoto doméstico em lagoas de polimento, considerando que a produção por biomassa algal de bioetanol e o biodiesel são os biocombustíveis líquidos de destaque no cenário sustentável. O tratamento de efluentes com microrganismos fotossintéticos pode se beneficiar do conhecimento proveniente do uso de microalgas para a produção de biocombustíveis, suplementos alimentares ou fármacos verdes e da fisiologia microbiana de bactérias fotossintéticas. Da mesma forma, as águas residuárias consideradas como fonte de nutrientes e carbono inorgânico são promissoras para a produção de biomassa algal. Este tratamento, é movido por energia solar e realizado por complexas interações entre microalgas, cianobactérias, bactérias heterotróficas e autotróficas, que exercem múltiplos efeitos sinérgicos e antagônicos durante o tratamento de efluentes. Logo, os sistemas de tratamento à base de microalgas podem reduzir os custos de tratamento de águas residuárias por meio da recuperação de seu material inerente e recursos de energia.

Ademais, se faz necessário também avaliar, identificar e quantificar as espécies fitoplanctônicas presentes nestes sistemas de tratamento, de forma que sejam feitas novas correlações a fim de distinguir as principais espécies de cianobactérias, estas que por sua vez são microorganismos potencialmente produtoras de cianotoxinas, com o objetivo de minimizar a liberação nos corpos aquáticos. Este é um grande problema ambiental, logo é imprescindível que o tratamento do esgoto doméstico seja eliminar ou minimizar a presença de constituintes indesejáveis antes de serem dispostos no meio ambiente em consonância com as legislações vigentes de condições e padrões de lançamento de efluentes, visando à preservação da diversidade biológica.

\section{Referências}

Ahmad, A. L., Mat Yasin, N. H. M., Derek, C. J. C., \& Lim J. K. (2011). Microalgae as a sustainable energy source for biodiesel production: a review. Renewable and Sustainable Energy Reviews, 15, $584-593$. 
Amengual-Morro, C., Niell, G. M., \& Martínez-Taberner, A. (2012). Phytoplankton as bioindicator for waste stabilization ponds. J Environ Manage, 95: 571576.

Amon, T. et al. (2017). Biogas production from maize and dairy cattle manure-Influence of biomass composition on the methane yield. Agriculture, Ecosystems and Environment, v. 118 (1), 173-182.

Apha, Awwa. WPCF. Standard methods for the examination of water and wastewater. (22a ed.), Washington, DC. American Public Health Association. American Water Works Association, Water Pollution control Federation, 2012.

Bahadar, A, \& KhaN, M. Bilal. (2013). Progress in energy from microalgae: A review. Renewable And Sustainable Energy Reviews, $27,128-148$.

Barroso, J. C. A. J. Produção de biomassa de algas em lagoas de alta taxa alimentadas com esgoto sanitário com posterior separação por flotação por ar dissolvido. Universidade Federal do Rio Grande do Sul, 2015.

Bastos, R. K. X., Dornelas, F. L., Rios, E. N., Ruas, D. B., \& Okano, W. Y. Dinâmica da qualidade da água e da comunidade planctônica em lagoas de polimento. Estudo de caso no sudeste brasileiro. Revista AIDIS, 3(1), 97-107, 2010.

Benemann, J. R., \& Oswald, W. J. Systems and Economic Analysis of Microalgae Ponds for Conversion of $\mathrm{CO}_{2}$ to Biomass. Final report to the Department of Energy, Pittsburgh Energy Technology Center, p. DOE/PC/93204-T5, 1996.

Besha, A. T., Gebreyohannes, A. Y., Tufa, R. A., Bekele, D. N., Curcio, E., \& Giorno, L. (2017). Removal of emerging micropollutants by activated sludge process and membrane bioreactors and the effects of micropollutants on membrane fouling: A review. Journal of Environmental Chemical Engineering, 5, 23952414

Branco, S. M. Hidrobiologia Aplicada à Engenharia Sanitária. CETESB. (2a ed.), 1978.

Brasil. 2018 Relatório do balanço energético nacional. https://unica.com.br/wp-content/uploads/2019/06/Relatoio-Sintese.pdf

Buchauer, K. A comparison of two simple titration procedures to determine volatile fatty acids in influents to waste-water and sludge treatment process. Water SA, 24(1), 49-56. 1998 .

Camargo Valero, M. A. Nitrogen transformation pathways and removal mechanisms in domestic wastewater treatment by maturation ponds. Phd Thesis. School of Civil Engineering. The University of Leeds, Leeds. 156p. 2008.

Cavalcanti, P. F. Aplicação de reatores UASB e lagoas de polimento no tratamento de esgoto doméstico. João Pessoa: Gráfica Santa Marta, 2009. 172p.

Chi, Z., Zheng, Y., Jiang, A., \& Chen, S. (2011). Lipid production by culturing oleaginous yeast and algae with food waste and municipal wastewater in an integrated process. Appl Biochem Biotech, 165: 442-453.

Couto, E. A., Calijuri, M. L., Asseman, Y, P. P., Tango, M. D., \& Santiago, A. F. (2015). Influence of solar radiation on nitrogen recovery by the biomass grown in high rate ponds. Ecological Engineering, 81, 140-14.

Craggs, R. J. Advanced integrated wastewater ponds. In A. Shilton, Pond Treatment Technology, IWA Scientific and Technical Report Series. IWA, London, 282-310. 2005 .

Falco, P. B. Estrutura da comunidade microbiana (algas e bactérias) em um sistema de lagoas de estabilização em duas escalas temporais: nictimeral e sazonal. 2005. 137f. Tese (Doutorado em Hidráulica e Saneamento). Escola de Engenharia de São Carlos, Universidade de São Paulo, 2005. http://www.teses.usp.br/teses/disponiveis/18/18138/tde-20042006-081717/pt-br.php

Gonzalez-fernandez, C., Molinuevo-Salces, B., Garcia Gonzalez, M. C. (2011). Nitrogen transformations under different conditions in open ponds by means of microalgae-bacteria consortium treating pig slurry. Bioresource Technology, 102(2), 960-966.

Gris, L. R. S. et al. Produção de microalgas em fotobiorreator airlift. IX Oktoberfórum - PPGEQ, 2010.

Hoh, D., Watson, S., \& Kan, E. (2016) Algal biofilm reactors for integrated wastewater treatment and biofuel production: a review. Chem Eng 287 : 466-473.

Jones, J. G. Aguide to Methods in freshwatus, London, Freshwater Biological Association, 39, 112p.

Kardol, P., Campany, C. E., Souza, L., Norby, R. J., Weltzin, J. F., \& Classen, A. T. (2010). Climate change effects on plant biomass alter dominance patterns and community evenness in an experimental old-field ecosystem. Global Change Biology, 16(10), 2676-2687.

Kassab, G., Halalsheh, M., Klapwijk, A., Fayyad, M., \& Van Lier, J. B. (2010). Sequential anaerobic-aerobic treatment for domestic wastewater - A review. Bioresource Technology (101), 3299-3310.

Konig, A. Biologia de lãs lagunas de estabilización: algas. In: Sistemas de Lagunas de Estabilización. Mendonça, S. R., McGraw-Hill Santa Fé de Bogotá, D. C., Colômbia, Editorial Nomos S.A. 2000.

Larsdotter, K. Wastewater treatment with microalgae - a literature review. VATTEN, 62: 31-38, 2006.

Lee, J. Y., Yoo, C., Jun, S. Y., Ahn, C. Y., \& Oh, H. M (2010). Comparison of several methods for effective lipid extraction from microalgae. Bioresource Technology, 101, $75-\mathrm{S} 77$.

Leite, V. D. et al. (2005). Tratamento de águas residuárias em lagoas de estabilização para aplicação na fertirrigação. Revista Brasileira de Engenharia Agrícola e Ambiental, 9, 71-75. 
Li, Y., Chen, Y. F., Chen, P., Min, M., Zhou, W., Martinez, B., Zhu, J., \& Ruan, R. (2011). Characterization of a microalga Chlorella sp. well adapted to highly concentrated municipal wastewater for nutrient removal and biodiesel production. Bioresource Technology, 102, 5138-5144.

Low-decarie, E., Fussmann, G. F., \& Bell, G. (2011). The effect of elevated $\mathrm{CO}_{2}$ on growth and competition in experimental phytoplankton communities. Global Change Biology, 17(8), 2525-2535.

Low-decarie, E., Bell, G., Fussmann, G. F. (2015). $\mathrm{CO}_{2}$ alters community composition and response to nutrient enrichment of freshwater phytoplankton. Oecologia, v. 177(3), 875-883.

Madigan, M. T., Martinko, J. M., Dunlap, P. V., \& Clark, D. P. Microbiologia de Brock. Traduzido de Brock Biology of Microorganisms. (12a ed.), Artmed, 2010

Makarevičienė, V., Andrulevičiūtè, V, Skorupskaitè V, \& Kasperovičienė, J. (2011).Cultivation of Microalgae Chlorella sp. and Scenedesmus sp. as a Potentional Biofuel Feedstock . Environmental Research, Engineering and Management. 3(57), 21 - 27

Mara, D. Domestic wastewater treatment in developing countries. London: Earthscan, 2003. 293p.

Matheus, C. L., Gianotti, E. P., \& Morais, A. G (1989). Correlação entre clorofila, STV e DQO. Revista DAE, 49 (154), 20-23.

Metcalf \& Eddy. Wasterwater Engineering: Treatment and reuse. (5a ed.), McGraw-Hill International edition, 2012.

Olguín, E. J. Dual purpose microalgae-bacteria-based systems that treat wastewater and produce biodiesel and chemical products within a Biorefinery. Biotechnol $A d v$, 30: 1031-1046, 2012.

Park, J. B. K. E Craggs, R. J. (2011). Algal production in wastewater treatment high rate algal ponds for potential biofuel use. Water Science and Technology, 63(10), 2403-2410.

Park, J. B. K., Craggs, R. J., \& Shilton, A. N. (2011). Recycling algae to improve species control and harvest efficiency from a high rate algal pond. Water research. 45.

Pearson, H., Microbial Interactions in facultative and maturation ponds. In: Mara, D., Horan, N. J. The Hand Book of Water and Wastewater Microbiology. London: Academic Press, 2005. 449-458.

Pereira, A. S. et al. (2018). Metodologia da pesquisa científica. UFSM. https://repositorio.ufsm.br/bitstream/handle/1/15824/Lic_Computacao_MetodologiaPesquisa-Cientifica.pdf?sequence=1.

Perez-Garcia, O. et al. (2011). Heterotrophic cultures of microalgae: Metabolism and potential products. Water Research, 45(1), 11-36.

Pittman, J. K., Dean, A. P., \& Osundeko, O. (2011). The potential of sustainable algal biofuel production using wastewater resources. Bioresource Technology, $102,17-25$.

Ramos, L. P. et al. (2017). Biodiesel: Matérias-Primas, Tecnologias de Produção e Propriedades Combustíveis. Revista Virtual de Quimica, 9(1), 317-369.

Ribeiro, P. C. Análise de fatores que influenciam a proliferação de cianobactérias e algas em lagoas de estabilização. 2007. 106f. Dissertação (Mestrado em Engenharia Civil), Universidade Federal de Campina Grande, Campina Grande - PB, 2007.

Richmond, A. Progress in Phycological Research, Round/ Chapman eds., Biopress Ltda., 7: 1-62, 2004.

Soldatelli, V. F., \& Schwarzbold, A. (2010). Comunidade fitoplanctônica em lagoas de maturação, Caxias do Sul, Rio Grande do Sul, Brasil. Iheringia Série Botânica, 65 (1), 75-86.

Santiago, A. F. Avaliação Do Desempenho De Lagoas De Alta Taxa No Tratamento De Esgoto Pré-Desinfectado Submetidas a Diferentes Níveis De Radiação Solar. [s.l.] Universidade Federal de Viçosa, 2013.

Shilton, A. Pond Treatment Technology. IWA Publishing. London, 2005, 479p.

Subashchandrabose, S. R. et al. (2011). Consortia of cyanobacteria/microalgae and bacteria: Biotechnological potential. Biotechnology Advances, 29(6), 896907.

Sutherland, D. L., Howard-Williams, C., Turnbull, M. H., Broady, P. A., \& Craggs, R. J. (2015). The effects of $\mathrm{CO}_{2}$ addition along a pH gradient on wastewater microalgal photo-physiology, biomass production and nutrient removal. Water Research, 70, 9-26.

Tabatabaei, M., Tohidfar, M., Jouzani, G. S., Safarnejad, M., \& Pazouki, M. (2011). Biodiesel production from genetically engineered microalgae: Future of bioenergy in Iran. Renewable And Sustainable Energy Reviews, 15, 1918-1927.

Von Sperling, M. Lagoas de Estabilização: Princípios do Tratamento Biológico de Águas Resíduárias. Belo Horizonte: UFMG, 2002.196p.

Wang, R., Balkanski, Y., Boucher, O., Ciais, P., Schuster, G. L., Chevallier, F., \& Tao, S. (2016). Estimation of global black carbon direct radiative forcing and its uncertainty constrained by observations. 121(10), Journal of Geophysical Research. 5948-5971.

Zhang, C. M.; Mao, Z. G.; Wang, X.; Zhang, J. H.; Sun, F. B.; \& Tang, L. (2010). Effective ethanol production by reutilizing waste distillage anaerobic digestion effluent in an integrated fermentation process coupled with both ethanol and methane fermentations. Bioprocess Biosyst Eng, 33: 1067-1075. 